\title{
A new Cadmium(II) complex with bridging dithiolate ligand: synthesis, crystal structure and antifungal activity study
}

\author{
Mahesh Kumar Singh ${ }^{1}$, Sanjit Sutradhar ${ }^{1}$, Bijaya Paul ${ }^{1}$, Suman Adhikari ${ }^{2}$, Folguni Laskar ${ }^{3}$, Raymond J. \\ Butcher $^{4}$, Sandeep Acharya ${ }^{5}$ and Arijit Das ${ }^{6 *}$ \\ ${ }^{1}$ Department of Chemistry, Tripura University, Suryamaninagar-799130, Tripura, India. \\ ${ }^{2}$ Department of Chemistry, Govt. Degree College, Dharmanagar, Tripura(N), India. \\ ${ }^{3}$ Advanced level Institutional Biotech Hub, Karimganj College, Karimganj, Assam, India. \\ ${ }^{4}$ Department of Inorganic and Structural Chemistry, Howard University, WashingtonDC20059 \\ ${ }^{5}$ Department of Botany, R.K.Mahavidyalaya, Kailashahar, Unakoti Tripura, Tripura, India. \\ ${ }^{6}$ Department of Chemistry, Ramthakur College, Agartala, Tripura(W), India.
}

\section{*Corresponding Author: arijitdas78chem@gmail.com}

Abstract: A new polymeric complex of $\mathrm{Cd}(\mathrm{II})$ with 1,1-dicyanoethylene- 2,2-dithiolate [ i$\left.\mathrm{MNT}^{2-}=\left\{\mathrm{S}_{2} \mathrm{C}: \mathrm{C}(\mathrm{CN})_{2}\right\}^{2-}\right]$ as a bridging ligand has been synthesized and characterized on the basis of spectroscopy and single-crystal X-ray diffraction analysis. Single crystal X-ray diffraction analysis reveals that the cadmium (II) complex is six coordinated 1D polymeric in nature. Biological screening effects in vitro of the synthesized polymeric complex has been tested against five fungi Synchitrium endobioticum, Pyricularia oryzae, Helminthosporium oryzae, Candida albicans(ATCC10231), Trichophyton mentagrophytes by the disc diffusion method. In vitro antifungal screening indicates that the complex exhibits fungistatic and fungicidal antifungal activity whereas $\mathrm{K}_{2} \mathrm{i}-\mathrm{MNT} . \mathrm{H}_{2} \mathrm{O}$ became silent on Synchitrium endobioticum, Pyricularia oryzae, Helminthosporium oryzae, Candida albicans (ATCC10231), Trichophyton mentagrophytes.

Keywords: Polymeric complex, Cd(II), 1,1-dithiolate, X-ray diffraction and antifungal activity study.

\section{Introduction:}

Construction of new coordination polymeric framework of $\mathrm{Cd}(\mathrm{II})$ is of interest due to their fascinating network topologies and their potential application in magnetism, luminescence, adsorption, catalysis, etc [1]. The biological significance of cadmium is based on the fact that its occurrence in a living being can critically alter its metabolism, giving rise to sharp intoxication. Thus it has been classified among the toxic elements [2]. Cadmium can be found in living beings as part of complexes with ligands and its toxic nature is due to coordination disrupting the biological functions of these ligands. Cadmium compounds can cause harm to kidney, central 
nervous system and are carcinogenic for connective tissue, lungs and liver [3]. Due to human activities cadmium concentration steadily increases leading to development of appropriate chelating ligand for its intoxication [4]. The capability to coordinate via sulphur is enhanced for cadmium as compared to zinc. Moreover, chelating sulfur donors are in fact under study as antidotes in cadmium(II) poisoning [5].

The electronic configuration $\left(\mathrm{d}^{10}\right)$ and size of cadmium(II) obviously favour its attraction for soft donor atoms as the $\mathrm{Cd}^{2+}$ ion is considered a soft Lewis acid. $\mathrm{Cd}(\mathrm{II})$ is to exhibit coordination numbers from three to eight. Owing to the larger size, $\mathrm{Cd}(\mathrm{II})$ shows coordination number six more easily than $\mathrm{Zn}$ (II) [6]. Cadmium complexes seem to be more interesting from a structural point of view because of the ability of these cations to modify both coordination numbers and geometries and also Cd involved in many biological molecules [7].

Systematic design of complexes with novel architectures and desired functionalities with principles of crystal engineering is most demanding subjects in current coordination chemistry. Judicious choice of ligands, bridging ligands, different metal ions, can tune the structure of coordination polymeric frameworks [8]. Sulphur-based 1,1-dithiolate ligands have proved promising when reacted with transition metals to give rise to a different of metal clusters possessing attractive conductive properties. Structural chemistry of dithiolate ligands is extraordinarily diverse and has important advantages over other organic ligands. Dithiolate ligands are widely engaged in transition metal chemistry, and the flexibility of sulfur as a ligand in transition metal chemistry has been widely recognized [9]. A great deal of interest has been evoked in coordination compounds of unsaturated sulfur chelating ligands, 1,1-dicyanoethylene2,2-dithiolate, and related molecules owing to interesting chemical properties and possible applications [10]. 1,1-Dicyanoethylene-2,2-dithiolate ion, by virtue of their chelating and bridging behaviours depending on the metal ion leading to various coordination modes and they may connect metal ions in different directions [11]. In spite of this growing range of coordination polymeric complexes, there are still many more coordination polymers which are yet to be synthesised and explored; in particular ligands with sulphur coordination sites have received far less attention.

We have initiated an investigation into the design, synthesis, and characterization of transition metal complexes containing dithiolate ligands and exploring the antifungal activity of the 
synthesized complex. One of our aims is to study the coordination properties of the $\mathrm{N}$ and $\mathrm{S}$ donors in $\mathrm{i}-\mathrm{MNT}^{2-}$. In our previous study [12], the interaction of dithiolate with different metal ions has been studied. To the best of our knowledge there is no report on polymeric complexes of Cd(II) involving bridging 1,1-dithiolate ligand. As an extension of our previous works we report here on the synthesis, characterization, and antifungal activities of a new polymeric complex of cadmium(II) (1) with sulfur donors. We hope the study would offer helpful information about the nature of cadmium(II) complexes with sulfur containing biological ligands.

\section{Experimental}

\subsection{Materials and methods}

All chemicals were of E. Merck of GR or equivalent grade and used without purification. Infrared spectra were recorded in $\operatorname{KBr}(4000-400 \mathrm{~cm}-1)$ and in CsI (600-50 cm-1) on a Bomen DA-8 FT-IR spectrophotometer. NMR spectra were recorded on a Bruker Avance DRX 300 FTNMR spectrophotometer. $\mathrm{K} 2 \mathrm{i}-\mathrm{MNT} \cdot \mathrm{H} 2 \mathrm{O}$ was prepared by a known literature procedure [13]. Crystal data were solved using the direct methods program SHELXS-97 [14a]. All nonsolvent heavy atoms were located using difference Fourier syntheses. The structures were refined against F2 with SHELXL [14b-c], in which all data collected was used counting negative intensities. All nonsolvent heavy atoms were refined anisotropically.

\section{Results and Discussion:}

\section{Synthesis of the complex 1:}

The synthesis of the complex CP 1 was accomplished as shown in Scheme 1.

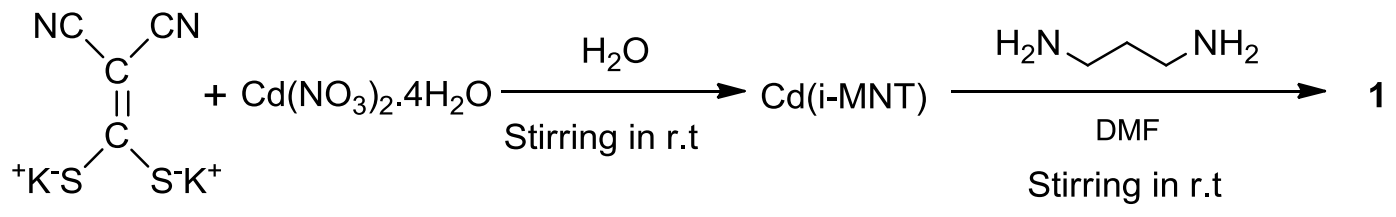

Scheme 1. Synthesis of 1.

$\mathrm{Cd}\left(\mathrm{NO}_{3}\right)_{2}{ }^{*} \mathrm{H}_{2} \mathrm{O}(0.005 \mathrm{M})$ in $50 \mathrm{~mL}$ distilled water was added slowly to $\mathrm{K}_{2} \mathrm{iMNT} . \mathrm{H}_{2} \mathrm{O}(0.005 \mathrm{M})$ in $20 \mathrm{~mL}$ water with constant stirring for 30 mins. The complex $\{\mathrm{Cd}(\mathrm{iMNT})\}$ thus obtained 
filtered by suction and washed successively with water, alcohol and ether and dried in vacuo. After that Cd(iMNT) (0.03 M) dissolved in DMF (50 mL) and 1,3-diaminopropane (tn) (0.03 M) added to it with constant stirring. Stirring was further continued for $2 \mathrm{hr}$. The reaction mixture was kept for 15 days to obtain the yellow crystalline complex CP $\mathbf{1}$.

IR and NMR: The observations in the IR and ${ }^{1} \mathrm{H}$ NMR spectra have importance for study of interaction between ligand and metal ion. The infra-red spectra of ligand and its metal complex 1 (CP 1) were recorded in the range of $400-4000 \mathrm{~cm}^{-1}$. CP 1 exhibit a group of broad band in the range 3251-3316 $\mathrm{cm}^{-1}$ attributed to $v(\mathrm{~N}-\mathrm{H}$ ) (asymmetric and symmetric) stretching modes. In the FT-IR spectrum of the metal complex 1 (CP 1) (KBr discs) show strong band at $2200 \mathrm{~cm}^{-1}$ due to the $v_{\mathrm{CN}}$ stretching. The $\mathrm{N}-\mathrm{H}$ bending (scissoring) vibration mode is observed in the range $1632 \mathrm{~cm}^{-1}$ for the CP 1. The $v(\mathrm{C}=\mathrm{C})$ absorption band appearing at $1360 \mathrm{~cm}^{-1}$ in $\mathrm{K}_{2} \mathrm{i}-\mathrm{MNT}$ is observed in the range 1351-1377 $\mathrm{cm}^{-1}$. The positive shifts of $\sim 17 \mathrm{~cm}^{-1}$ in $v(\mathrm{C}=\mathrm{C})$ suggest that resonance form is more dominant in the isomalononitrile dithiolate complexes. Hence, it can be concluded that the sulphur of the isomalononitrile is involved in metal coordination. In the IR spectrum $\mathrm{K}_{2} \mathrm{i}-\mathrm{MNT}$ a band at $960 \mathrm{~cm}^{-1}$ with a shoulder at $985 \mathrm{~cm}^{-1}$ is observed due to $\left(=\mathrm{CS}_{2}\right)$ group. The corresponding band and shoulder in the mixed ligand complex is shifted to lower frequencies and are found in the 937 regions. This implies coordination of the metal to the thiolate. The $v(\mathrm{C}-\mathrm{S})$ band occurring in the spectrum of CP 1 is $870 \mathrm{~cm}^{-1}$ is higher than that of $\mathrm{K}_{2 \mathrm{i}}-\mathrm{MNT}$ at $\left(860 \mathrm{~cm}^{-1}\right)$. The bands in the region $618-485 \mathrm{~cm}^{-1}$ are assigned to the $\mathrm{Cd}-\mathrm{S}$ vibrations [15].

The ${ }^{1} \mathrm{H}$ NMR spectra was carried out in DMSO d6 solvent. The complex CP 1 shows a broad NMR signals at $\delta 8.07 \mathrm{ppm}$ and $7.78 \mathrm{ppm}$ which suggest the presence of amine protons. The ${ }^{1} \mathrm{H}$ NMR spectrum of CP 1 shows a singlet peaks at 3.04 ppm and $2.25 \mathrm{ppm}$, multliplet at $2.55 \mathrm{ppm}$ and $1.50 \mathrm{ppm}$, The appearance of these resonances indicates that some unexpected compound formation occurs during the reaction medium. Thus the simple NMR spectrum did not give us a clear answer concerning the structure of the product. To solve the structure, crystal of complex $\mathbf{1}$ was mounted on a thin glass fiber for the X-ray diffraction analysis. 
Table 1. Crystal data and structure refinement for CP 1.

Identification code

Empirical formula

Formula weight

Temperature

Wavelength

Crystal system

Space group

Unit cell dimensions

Volume

Z

Density (calculated)

Absorption coefficient

$\mathrm{F}(000)$

Crystal size

Theta range for data collection

Index ranges

Reflections collected

Independent reflections

Completeness to theta $=25.500^{\circ}$

Absorption correction

Refinement method

Data / restraints / parameters

Goodness-of-fit on $\mathrm{F}^{2}$

Final $\mathrm{R}$ indices [I $>2 \operatorname{sigma}(\mathrm{I})]$

$\mathrm{R}$ indices (all data)

Extinction coefficient

Largest diff. peak and hole shelx

C16 H18 Cd N8 S4

563.02

100(2) K

$0.71073 \AA$

Orthorhombic

$\mathrm{Pcc} \mathrm{n}$

$a=14.7152(10) \AA \quad \alpha=90^{\circ}$.

$\mathrm{b}=17.3633(12) \AA \quad \beta=90^{\circ}$.

$\mathrm{c}=8.4214(6) \AA \quad \gamma=90^{\circ}$.

2151.7(3) $\AA^{3}$

4

$1.738 \mathrm{Mg} / \mathrm{m}^{3}$

$1.424 \mathrm{~mm}^{-1}$

1128

$0.550 \times 0.460 \times 0.420 \mathrm{~mm}^{3}$

2.768 to $31.458^{\circ}$.

$-21<=\mathrm{h}<=21,-25<=\mathrm{k}<=25,-12<=\mathrm{l}<=12$

40436

$3429[\mathrm{R}(\mathrm{int})=0.0202]$

$99.7 \%$

Semi-empirical from equivalents

Full-matrix least-squares on $\mathrm{F}^{2}$

3429 / 0 / 140

1.076

$\mathrm{R} 1=0.0213, \mathrm{wR} 2=0.0590$

$\mathrm{R} 1=0.0218, \mathrm{wR} 2=0.0593$

$\mathrm{n} / \mathrm{a}$

0.994 and -0.370 e. $\AA^{-3}$

X-ray crystallography: The bifunctional ligand i-mnt ${ }^{2-}$ represent supramolecular connectors that can generate infinite networks and metal-organic frameworks. It can coordinate to metal atoms through sulfur and nitrogen atoms only,[16] or through both sulfur and nitrogen atoms. 
The i-mnt ${ }^{2-}$ may present various coordination modes, leading to the formation of mono-nuclear, $d i$-nuclear, metal-organic frameworks or coordination polymers. A small yellow crystal of complex CP 1 was mounted on a thin glass fiber for the X-ray diffraction analysis and the resulting compound crystallizes in the Orthorhombic space group, P c c n (see Table 1). The crystal data, data collection parameters and analysis statistics are listed in the Table 1. The crystal structure of CP 1 shows 1,1-dicyanoethylene- 2,2-dithiolate (i-mnt ${ }^{2-}$ ) assisted 2-D polymer. The SCHAKAL plot with atom numbering scheme is shown in figure 1.

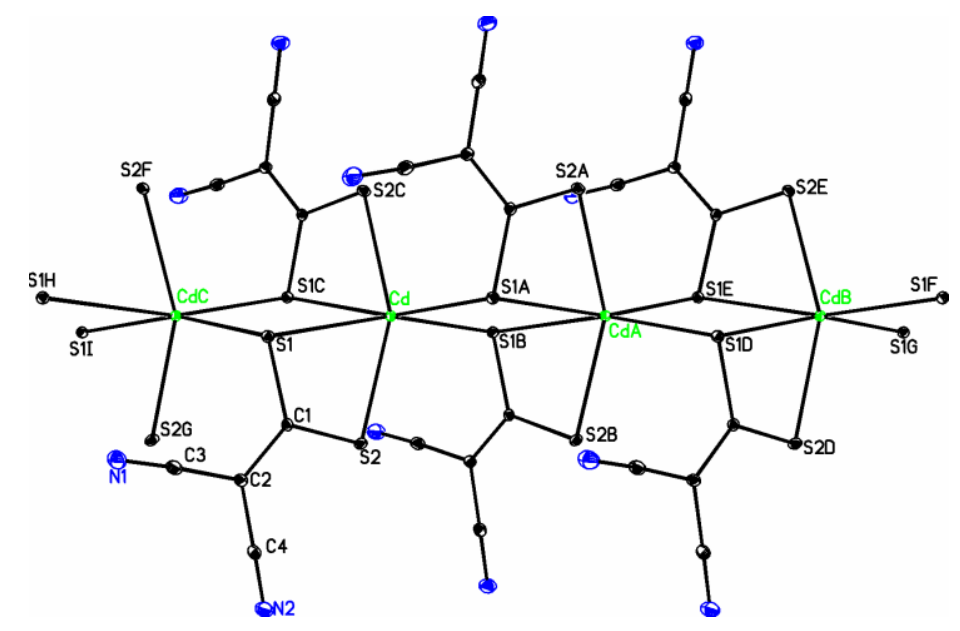

Figure 1. SCHAKAL plot of 1 with atom numbering scheme.

Fig. 1 shows that in the polymeric chain each cadmium cation is hexacoordinated, having the distorted octahedral coordination. Selected bond distances and angles are listed in Table 2. The crystal structure consists of linear $\mathrm{Cd}(\mathrm{i}-\mathrm{mnt})_{2}{ }^{2}$ anions and $\left(\mathrm{C}_{4} \mathrm{H}_{9} \mathrm{~N}_{2}\right)$ cations in the unit cell. The cyclic hexahydropyrimidine cations $\left(\mathrm{C}_{4} \mathrm{H}_{9} \mathrm{~N}_{2}\right)$ produce during the reaction between 1, 3-diamino propane and N,N-dimethyl foramide [17] which was evident from both NMR spectra and crystal structure. The packing diagram (Figure 2) shows that the anions exist discretely and are arranged in a line. The $\mathrm{Cd}$ atom is surrounded by six sulphur atoms coordinated in a distorted octahedral. The cadmium metal center adopts a distorted octahedral coordination geometry with the bond angles deviates from $90^{\circ}$ or $180^{\circ}\left\{\mathrm{S}(1) \# 2-\mathrm{Cd}(1)-\mathrm{S}(1) \# 1\right.$ is $164^{\circ}, \mathrm{S}(1) \# 2-\mathrm{Cd}(1)-\mathrm{S}(1) \# 3$ is $\left.84^{\circ}\right\}$.The six Cd-S bond distances are $\{2.57(3) \AA, 2.57(3) \AA, 2.72(3) \AA, 2.72(3) \AA, 2.86(3) \AA$ and 2.86(3) $\AA$ \} different. Of the six Cd-S distances compared, the 1,1-dicyanoethylene-2,2-dithiolate ligand chelated $\{\mathrm{Cd}(1)-\mathrm{S}(2)$ and $\mathrm{Cd}(1)-\mathrm{S}(2) \# 1)\}$ is shorter $\{2.57(3) \AA$ \} than other $\mathrm{Cd}-\mathrm{S}$ distances. Cd-S bond distances $\{\mathrm{Cd}(1)-\mathrm{S}(1) \# 1 \quad 2.86(3) \AA$ and $\mathrm{Cd}(1)-\mathrm{S}(1) \quad 2.86(3) \AA$ are comparably longer than those of bridging thiolate in [Cd4( $\mu-\mathrm{SPh}) 8]$ av. 2.538(3) $\AA$ \} [18], [Cd(SPh)2(tmdp)2]n \{av. 2.444(5) $\AA$ \} and [Cd(SC6H4Me4)2(tmdp)2]n \{av. 2.438(5) $\AA$ \} [19]. 
Elongation of M-S distances is usually observed when the coordination numbers of metal are increased. The cause may be that the higher the coordination number, the lower the bond order. The Cd...Cd distance along the molecule is equal to $4.211 \AA$. In between thiolate $\mathrm{S}$ and $\mathrm{N}$ only $\mathrm{S}$ are involved in coordination with cadmium which is different than our previous reported $\mathrm{Cd}(\mathrm{II})$ complexes [12 h-i]. To the best of our knowledge, there are only few examples of X-ray crystal structures of transition metal coordination compounds of $\mathrm{Cd}(\mathrm{II})$ where cadmium is coordinated to six sulphur atoms[20]. In some cases however, only one of the functional groups/atoms of the heteroleptic ligand will coordinate [21]. Sometimes the lack of ability for both functional groups/atoms to coordinate to the metal centre can be associated to the preference of a metal for certain donor atoms, such as sulphur (soft) or oxygen (hard). This discrepancy between sulphur donors and nitrogen donors suggests that dithiolate ligands could be more successful in generating polymeric complexes. Sulphur atoms of i-mnt ${ }^{2-}$ executes 1,1-dicyanoethylene-2,2dithiolate -assisted polymeric assembly shown in figure 2.

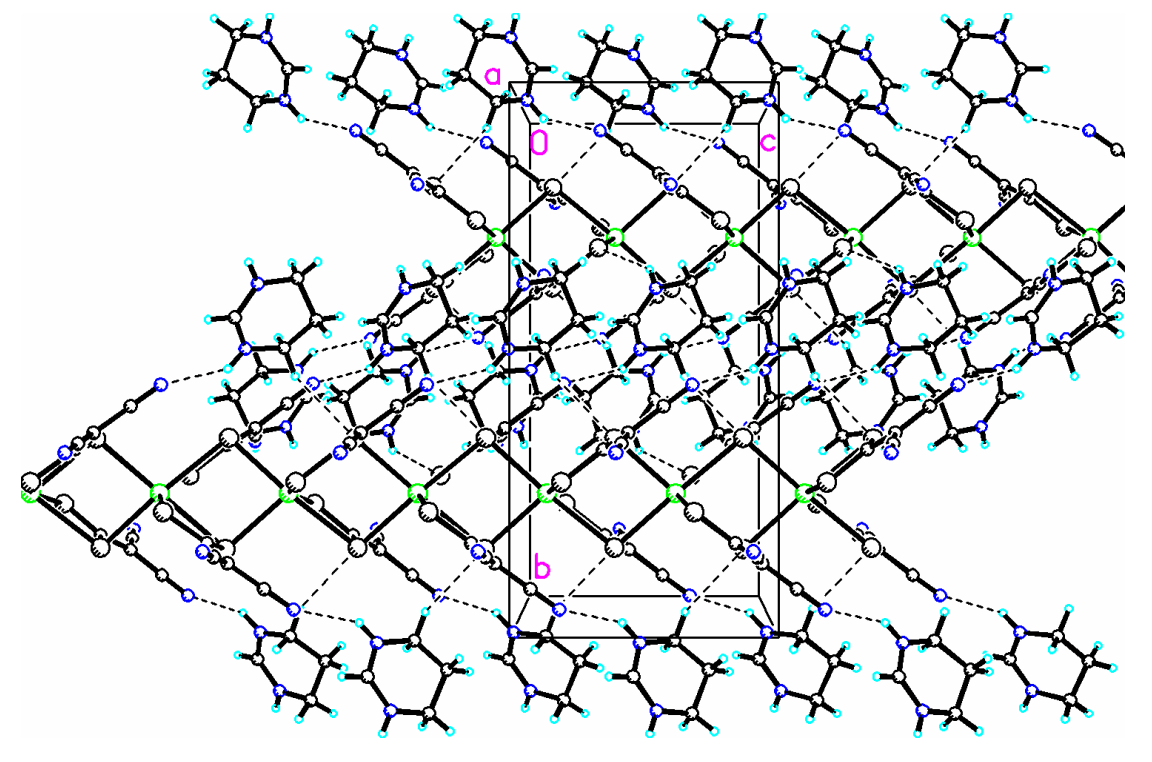

Figure 2. Molecular packing of the complex. Hydrogen bonds are shown as thin dashed lines.

The crystal structure of $\mathbf{1}$ is stabilized by hydrogen bonds. Intermolecular $\mathrm{N}-\mathrm{H}-\mathrm{N}$ hydrogen bonds between cyclic $\left(\mathrm{C}_{4} \mathrm{H}_{9} \mathrm{~N}_{2}\right)$ cations and non-coordinating nitrogen atom of the 1,1dicyanoethylene-2,2-dithiolate strengthens the coordination complex. These intermolecular hydrogen bonds bind the molecules in an infinite chain shown in (Fig.2). 
Table 2. Bond lengths $[\AA]$ and angles $\left[{ }^{\circ}\right]$ for CP1.

\begin{tabular}{lllr}
\hline $\mathrm{Cd}(1)-\mathrm{S}(2)$ & $2.5760(3)$ & $\mathrm{S}(2)-\mathrm{Cd}(1)-\mathrm{S}(2) \# 1$ & $155.081(14)$ \\
$\mathrm{Cd}(1)-\mathrm{S}(2) \# 1$ & $2.5761(3)$ & $\mathrm{S}(2)-\mathrm{Cd}(1)-\mathrm{S}(1) \# 2$ & $99.478(10)$ \\
$\mathrm{Cd}(1)-\mathrm{S}(1) \# 2$ & $2.7168(3)$ & $\mathrm{S}(2) \# 1-\mathrm{Cd}(1)-\mathrm{S}(1) \# 2$ & $98.836(10)$ \\
$\mathrm{Cd}(1)-\mathrm{S}(1) \# 3$ & $2.7168(3)$ & $\mathrm{S}(2)-\mathrm{Cd}(1)-\mathrm{S}(1) \# 3$ & $98.835(10)$ \\
$\mathrm{Cd}(1)-\mathrm{S}(1) \# 1$ & $2.8699(3)$ & $\mathrm{S}(2) \# 1-\mathrm{Cd}(1)-\mathrm{S}(1) \# 3$ & $99.477(10)$ \\
$\mathrm{Cd}(1)-\mathrm{S}(1)$ & $2.8699(3)$ & $\mathrm{S}(1) \# 2-\mathrm{Cd}(1)-\mathrm{S}(1) \# 3$ & $84.952(14)$ \\
$\mathrm{S}(1)-\mathrm{C}(1)$ & $1.7337(13)$ & $\mathrm{S}(2)-\mathrm{Cd}(1)-\mathrm{S}(1) \# 1$ & $93.980(10)$ \\
$\mathrm{S}(1)-\mathrm{Cd}(1) \# 4$ & $2.7168(3)$ & $\mathrm{S}(2) \# 1-\mathrm{Cd}(1)-\mathrm{S}(1) \# 1$ & $66.344(9)$ \\
$\mathrm{S}(2)-\mathrm{C}(1)$ & $1.7261(13)$ & $\mathrm{S}(1) \# 2-\mathrm{Cd}(1)-\mathrm{S}(1) \# 1$ & $164.934(14)$
\end{tabular}

Antifungal activity study of the CP 1: Investigation of the in vitro antifungal activity of synthesized metal complex was done by the disc diffusion method [22].The antifungal properties of the ligand $\mathrm{K}_{2} \mathrm{i}-\mathrm{MNT} . \mathrm{H}_{2} \mathrm{O}$ and its cadmium complex were investigated against plants and animal fungi, namely Synchitrium endobioticum (wild type), Pyricularia oryzae (wild type), Helminthosporium oryzae (wild type), Candida albicans (ATCC10231), Trichophyton mentagrophytes (clinically isolated) and matched with ligand $\mathrm{K}_{2 \mathrm{i}} \mathrm{-MNT}$ and standard sample Griseofulvin $(10 \mu \mathrm{g} / \mathrm{disc})$. In this study the strains were maintained and confirmed on Sabouraud Dextrose agar.

In a typical disc diffusion process, a 20\% (w/v) stock solution of each dry extract (complex 1 and its primary ligand) was prepared in pure dimethyl sulphoxide (DMSO). For moulds, suspensions of mature spores were acquired by gently washing the surface of solid media with a $0.05 \%(\mathrm{v} / \mathrm{v})$ solution of Tween 80 and the resulting suspension was adjusted to $10^{6}$ spores $\mathrm{mL}^{-}$ ${ }^{1}$.WhatmanNo.4 filter paper discs $(6 \mathrm{~mm}$ diameter) were positioned on the inoculated agar surfaces and soaked with $15 \mu \mathrm{l}$ of stock solutions. Griseofulvin $(10 \mu \mathrm{g} / \mathrm{disc})$ discs were used as positive controls while pure DMSO $(15 \mu \mathrm{l})$ was used as a negative control. The plates were observed after $96 \mathrm{~h}$ at $25^{\circ} \mathrm{C}$ for moulds. All the readings based on 5 replicates. The results are accumulated in Table 3. 
Table 3: Anti-Fungal activity of CP 1

\begin{tabular}{|c|c|c|c|c|c|}
\hline \multirow{2}{*}{$\begin{array}{c}\text { Material } \\
(1 \mathrm{mg} / \mathrm{mL})\end{array}$} & \multicolumn{5}{|c|}{ Minimum Inhibitory Conc. (mg/mL) } \\
\cline { 2 - 6 } & $\begin{array}{c}\text { Pyriculari } \\
\text { aoryzae }\end{array}$ & $\begin{array}{c}\text { Helminthosporium } \\
\text { oryzae }\end{array}$ & $\begin{array}{c}\text { Synchitrium } \\
\text { endobioticum }\end{array}$ & $\begin{array}{c}\text { Candida } \\
\text { albicans }\end{array}$ & $\begin{array}{c}\text { Trichophyton } \\
\text { mentagrophytes }\end{array}$ \\
\hline $\mathrm{CP} 1$ & $08(\mathrm{FC})$ & 18 & $12(\mathrm{FS})$ & $\mathrm{NE}$ & $\mathrm{NE}$ \\
\hline $\mathrm{K}_{2}-\mathrm{iMNT.H}{ }_{2} \mathrm{O}$ & $\mathrm{NE}$ & $\mathrm{NE}$ & $\mathrm{NE}$ & $\mathrm{NE}$ & $\mathrm{NE}$ \\
\hline Control (DMSO) & $\mathrm{NE}$ & $\mathrm{NE}$ & $\mathrm{NE}$ & $\mathrm{NE}$ & $\mathrm{NE}$ \\
\hline $\begin{array}{c}\text { Griseofulvin } \\
(10 \mu \mathrm{g} / \text { disc })\end{array}$ & 0.1 & 0.1 & 0.3 & 0.2 & 0.4 \\
\hline
\end{tabular}

\section{All the readings based on 5 replicates \pm SEM, $(\mathrm{NE})=$ No effect}

Transition metal-based complexes containing $S$ donor atoms have gained increasing recognition due to their potential application in biological activity. The synthesized complex CP $\mathbf{1}$ and ligand $\left(\mathrm{K}_{2} \mathrm{iMNT} . \mathrm{H}_{2} \mathrm{O}\right)$ has been tested against five fungi Synchitrium endobioticum, Pyricularia oryzae, Helminthosporium oryzae, Candida albicans (ATCC10231), Trichophyton mentagrophytes on the basis of its minimum inhibitory concentration (M.I.C). The MIC value of the standard sample Griseofulvin is $0.1 \mathrm{mg} / \mathrm{mL}$. CP 1 shows highest fungicidal activity against Helminthosporium oryzae and shows no fungicidal activity against Candida albicans and Trichophyton mentagrophytes whereas its ligand $\left(\mathrm{K}_{2} \mathrm{iMNT} . \mathrm{H}_{2} \mathrm{O}\right)$ showed no effect on any fungi. Generally coordination of an organic ligand to metal centers amplifies its antifungal activities due to the greater lipophilic nature of the complex than the free ligand and metal ion which in fact is in agreement with the literature [23]. Due to overlapping of the ligand and metal ion orbitals intensifies the resonance of $\pi$ electrons and consequently increases the liposolubility of the complex with respect to free ligand [24]. This improved lipophilicity enhances the penetration of the complexes into lipid membrane and stops the metal binding sites on enzymes of microorganisms. The difference in the efficiency of polymeric complex CP $\mathbf{1}$ against different fungi depends either on the impermeability of the cells of the microbes or on changes in ribosome of microbial cells. The polymeric complex CP $\mathbf{1}$ has an advantage in the bioactivities of the free ligands and metal ions are combined and thus could make it more potent antifungal agents. 


\section{Conclusion:}

Sulphur-based metal complexes are significant classes of materials owing to their capability to produce materials for applications such as gas storage, catalysis, magnetism, conductivity, nonlinear optical responses, catalysis, and ionexchange etc. Even though it's being a great deal explored independently, very little has been achieved. Herein, we report the synthesis and crystal structure of a new polymeric complex of $\mathrm{Cd}(\mathrm{II})$ with sulfur donors and its antifungal study. Antifungal activity of CP $\mathbf{1}$ is observed with significant activity compared to K2i-MNT on $S$. endobioticum, P. oryzae, and H. oryzae, and proved to be crucial for the growth-inhibitor effect. Cadmium(II) ion is found to be diamagnetic as expected for $\mathrm{d}^{10}$ configuration as a result cadmium complex shows higher antifungal activity. There is enormous possibility to develop these potential outcomes through careful design and investigation of more sulphur-based ligands. Further exploration is in progress in our laboratory.

\section{Acknowledgments}

One of the author, Dr. Suman Adhikari, Department of Chemistry, Govt. Degree College, Dharmanagar, Tripura, India is grateful to UGC (MRP- No. F.5-333/201516/MRP/NERO/1074), Govt. of India for their financial assistance. The author is also grateful to the Dr. Amartya Kumar Pal, Asst. Professor, NEHU, Shillong for NMR spectroscopy.

\section{Funding}

This work was supported by the Science and Engineering Research Board [grant number SB/EMEQ - 014/2013], [grant number SERB/F/5537/2013-14 27/11/2013]. The authors wish to acknowledge the assistance of Dr. Matthias Zeller in the data collection and NSF [grant number 
0087210], Ohio Board of Regents [grant number CAP-491], and Youngstown State University for funds to purchase the diffractometer.

\section{References}

[1] (a) Y.B. Dong, R.C. Layland, M.D. Smith, Inorg. Chem. 38 (1999) 3056; (b) A. Mondal, G. Mostafa, A. Ghosh, Dalton Trans. (1999) 9; (c) A. Banerjee, R. Maiti, T. Chattopadhyay, Polyhedron, 29 (2010) 951; (d) N.L. Rosi, J. Eckert, M. Eddaoudi, D.T. Vodak, J. Kim, M. O’Keeffe, O.M. Yaghi, Science, 300 (2003) 1127; (e) S.K. Nune, P.K. Thallapally, A. Dohnalkova, C.Wang, J. Liu, G.J. Exarhos, Chem. Commun. 46 (2010) 4878; (f) I. Warad, M. Abdoh, N. Shivalingegowda, N. K. Lokanath, R. Salghi, M. Al-Nuri, S. Jodeh, S. Radi, B. Hammouti, J Mol. Struct. 1099 (2015) 323; (g) H. H. Lee, E. Lee, H. Ju, S. Kim, I. H. Park, S. S. Lee, Inorg. Chem. 55 (2016) 2634; (h) D. Z Wang, J. Z. Fan, D. Jia, C. C. Du, Cryst. Eng. Comm. 18 (2016) 6708; (i) N. Zhang, D. Liu, H. Zhang, J. Yu, Z. Wu, Q. Zhu, H. Zhou, RSC Adv.6 (2016) 86158.

[2] H. R. Pohl, H. G. Abadin, J. F. Risher, in Neurotoxicity of Cadmium, Lead and Mercury, Vol. 1 of Metal Ions in Life Sciencies, Eds A. Sigel, H. Sigel, R. K. O. Sigel, John Wiley \& Sons, Chichester, UK (2006) pp. 397-400.

[3] (a) P. Patnaik, 'A Comprehensive Guide to the Hazardous Properties of Chemical Substance', Wiley, New York, (1999); (b). National Library of Medicine, National Toxicology Information Program, (2003) Hazardous Substance Data Bank.

[4] S. Sen, P. Talukder, G. Rosair, S. Mitra, Struct. Chem. 16 (2005) 605.

[5]. (a) J.S. Casas, A. Sanchez, I. Bravo, S. Garcia-Fontan, E.E Castellano, M.M. lones, Inorg. Chim. Acta, 158 (1989) 119 (b) M.A. Romero-Molina, M.D. Gutirrez-Valuro, R. Lopez-Garzon, J.M. Salas-Peregrin, MJ. Arriortua, F.J. Zufiiga, Inorg. Chim. Acta, 136 (1987) 87.

[6] (a) M. Borsari. Cadmium: Coordination Chemistry. Encyclopedia of Inorganic and Bioinorganic Chemistry, p. 1, Wiley Online Library, Modena, (2014); (b) S. A. Al-Jibori, M. M.A. Al-Bayati, H. M. Gergees, C. Wagner, G. Hogarth, Inorg. Chim. Acta, 459 (2017) 73 
[7] M.J. Hendrick, M.T. May, M.J. Plishka, K.D. Robinson, Metals in Biological Systems, Ellis Horwood, Chichester (1992).

[8] (a) P. Wang, J. P. Ma, Y. B. Dong, R. Q. Huang, J. Am. Chem. Soc. 129 (2007) 10620 (b) K. Ono, M. Yoshizawa, T. Kato, K. Watanabe, M. Fujita, Angew. Chem., Int. Ed. 46 (2007) 1803

(c) X. L. Wang, C. Qin, E. B. Wang, Z. M. Su, Chem. Eur. J. 12 (2006) 2680 (d) W. L. Chen, Y. G. Li, Y. H. Wang, E. B. Wang, Z. M. Su, Dalton Trans. (2007) 4293.

[9] V.W.W. Yam, K.K.W. Lo, W.K.M. Fung, C.R. Wang, Coord. Chem. Rev. 17, 171 and refs. therein (1998).

[10] a) D. Coucouvanis. In Progress in Inorganic Chemistry, S.J. Lippard (Ed.), Vol. 11, p. 234, John Wiley, New York (1970); (b) R. Eisenberg. In Progress in Inorganic Chemistry, S.J. Lippard (Ed.), Vol. 12, p. 295, John Wiley, New York (1970); (c) D. Coucouvanis. In Progress in Inorganic Chemistry, S.J. Lippard (Ed.), Vol. 26, p. 301, John Wiley, New York (1979); [11] (a) L. Scheller, H. Werner, Z. Anorg. Allg. Chem., 638 (2012) 76; (b) J. Xiao, Y. Azuma, Y. Liu, G. Li, F. Wei, K.J. Tan, C. Kloc, H. Zhang, Y. Majima, Q. Zhang. Aust. J. Chem., 65 (2012) 1674.

[12] (a) M.K. Singh, R.C. Aggarwal, B. Singh. Synth. React. Inorg. Met.-Org. Chem., 15 (1985) 459; (b) M.K. Singh. Indian J.Chem. 30A (1991) 1070; (c) M.K. Singh. J. Indian Chem. Soc., 76 (1999) 148; (d) M.K. Singh. Indian J. Chem., 38A (1999) 1294; (e) M.K. Singh, A. Das, B. Paul. Transition Met. Chem. 30 (2005) 655; (f ) M.K. Singh, A. Das, B. Paul. J. Coord. Chem., 62, (2009) 2745; (g) M.K. Singh, S. Sutradhar, B. Paul, S. Adhikari, R.J. Butcher, S. Acharya, A. Das. J. Coord. Chem. 67 (2014) 3613; (h) M.K. Singh, S. Sutradhar, B. Paul, S. Adhikari, R.J. Butcher, S. Acharya, A. Das. J. Coord. Chem. 68 (2015) 1423. (i) M.K. Singh, S. Sutradhar, B. Paul, S. Adhikari, R.J. Butcher, S. Acharya, A. Das. J. Coord. Chem. 69 (2016) 168.

[13] K.A. Jensen, L. Henriksen. Acta Chem. Scand. 22 (1968) 1107.

[14] (a) G.M. Sheldrick. Acta Crystallogr., 46 (1990) 467; (b) G.M. Sheldrick. SHELXL-97: FORTRAN program for crystal structure refinement, Gottingen University, Germany, \{copyright\} (1997); (c). G.M. Sheldrick, SHELXL-97: FORTRAN Program for Crystal Structure Analysis, Gottingen University, Instit. Fr Anorganisheche Chemie der Universitat, Tammanstrasse 4, D-3400, Gottingen, Germany (1998).

[15] S. Chandra, U. Kumar. Spectrochim Acta, Part A, 61 (2005) 219.

[16] B.S. Kang, Z.N. Chen, C.Y. Su, Z. Lin, T.B. Wen. Polyhedron, 17 (1998) 2497. 
[17] (a) J. M. Locke, R. L. Crumbie, R. Griffith, T. D. Bailey, S. Boyd, and J. D. Roberts. J. Org. Chem. 72 (2007) 4156; (b) R. N. Butler, K. J. Fitzgerald, J. Chem. Soc. Perkin Trans. I, 155 (1989), (c) N. Aoyagi, Y. Furusho, Y. Sei, T. Endo, Tetrahedron, 69 (2013) 5476.

[18] I.G. Dance, R.G. Garbutt, D.C. Craig, M.L. Scudder. Inorg. Chem., 26 (1987) 4057.

[19] (a) P. Chakraborty, A. Guha, S. Das, E. Zangrando, D. Das. Polyhedron, 49 (2013) 12; (b) M.A. Sharif, G.R. Najafi. Acta Chim. Slov. 60, (2013) 138; (c) L. Saghatforoush, H.A. Rudbari, F. Nicolò, P. Asgari, F. Chalabian, M. Hasanzadeh, V. Panahiazar. Acta Chim. Slov. 60 (2013) 300; (d) F. Marandi, S. Teimouri, H.-K. Fun. Acta Chim. Slov., 60 (2013) 328.

[20] V.G. Young Jr., E.R.T. Tiekink, Acta Crystallogr. Sect. E, 58 (2002) 537.

[21] K.H. Kim, T. Ueta, T. Okubo, S. Hayami, H. Anma, K. Kato, T. Shimizu, J. Fujimori, M. Maekawa, T. Kuroda-Sowa, Chem. Lett. 40 (2011) 1184.

[22] (a) A. Barry. In Antibiotics in Laboratory Medicine, V. Lorian (Ed.), pp. 1-16, Williams and Wilkins, Baltimore, MD (1991). (b) T. Rosu, M. Negoiu, S. Pasculescu. Eur. J. Med. Chem. 45 (2010) 774.

[23] (a) Y. Anjaneyulu, R.P. Rao. Synth. React. Inorg. Met.-Org. Chem., 16 (1986) 257; (b) M. Montazerozohori, S. Zahedi, M.N. Esfahani, A. Naghiha. J. Ind. Eng. Chem., 20 (2014) 2463. [24] N. Dharmaraj, P. Viswanathamurthi, K. Natarajan. Transition Met. Chem., 26 (2001) 105. 


\title{
A new Cadmium(II) complex with bridging dithiolate ligand: synthesis, crystal structure and antifungal activity study
}

\author{
Mahesh Kumar Singh ${ }^{1}$, Sanjit Sutradhar ${ }^{1}$, Bijaya Paul ${ }^{1}$, Suman Adhikari ${ }^{2}$, Folguni Laskar ${ }^{3}$, Raymond J. \\ Butcher $^{4}$, Sandeep Acharya ${ }^{5}$ and Arijit Das $6 *$ \\ ${ }^{1}$ Department of Chemistry, Tripura University, Suryamaninagar-799130, Tripura, India. \\ ${ }^{2}$ Department of Chemistry, Govt. Degree College, Dharmanagar, Tripura(N), India. \\ ${ }^{3}$ Advanced level Institutional Biotech Hub, Karimganj College, Karimganj, Assam, India. \\ ${ }^{4}$ Department of Inorganic and Structural Chemistry, Howard University, WashingtonDC20059 \\ ${ }^{5}$ Department of Botany, R.K.Mahavidyalaya, Kailashahar, Unakoti Tripura, Tripura, India. \\ ${ }^{6}$ Department of Chemistry, Ramthakur College, Agartala, Tripura(W), India.
}

*Corresponding Author: arijitdas78chem@gmail.com

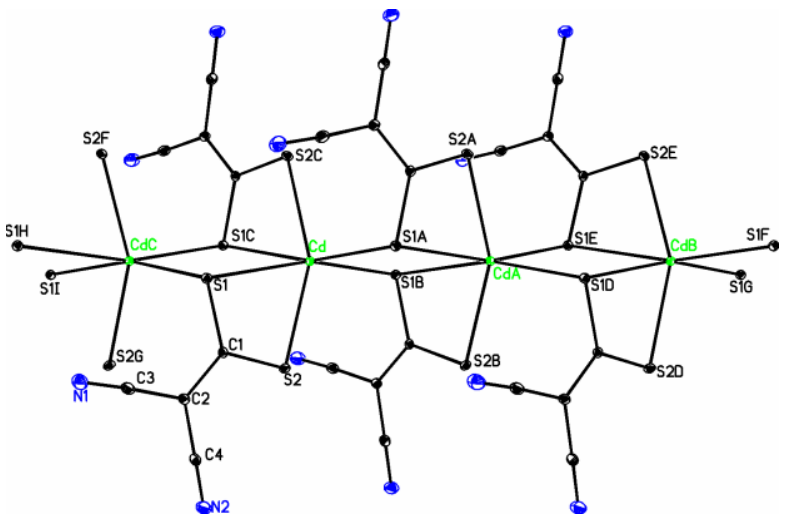

Abstract: A new polymeric complex of $\mathrm{Cd}(\mathrm{II})$ with 1,1-dicyanoethylene- 2,2-dithiolate [ i$\left.\mathrm{MNT}^{2-}=\left\{\mathrm{S}_{2} \mathrm{C}: \mathrm{C}(\mathrm{CN})_{2}\right\}^{2-}\right]$ as a bridging ligand has been synthesized and characterized on the basis of spectroscopy and single-crystal X-ray diffraction analysis. Single crystal X-ray diffraction analysis reveals that the Cadmium (II) complex is six coordinated 1D polymeric in nature. Biological screening effects in vitro of the synthesized polymeric complex has been tested against five fungi Synchitrium endobioticum, Pyricularia oryzae, Helminthosporium oryzae, Candida albicans(ATCC10231), Trichophyton mentagrophytes by the disc diffusion method. In vitro antifungal screening indicates that the complex exhibits fungistatic and fungicidal antifungal activity whereas $\mathrm{K}_{2} \mathrm{i}-\mathrm{MNT} . \mathrm{H}_{2} \mathrm{O}$ became silent on Synchitrium endobioticum, Pyricularia oryzae, Helminthosporium oryzae, Candida albicans (ATCC10231), Trichophyton mentagrophytes. 